\title{
Epigenetic reprogramming of immune cells in injury, repair, and resolution
}

\author{
Katarzyna Placek, ${ }^{1}$ Joachim L. Schultze, ${ }^{2,3}$ and Anna C. Aschenbrenner ${ }^{3}$ \\ ${ }^{1}$ Immunology and Metabolism, LIMES Institute, University of Bonn, Bonn, Germany. ${ }^{2}$ Platform for Single Cell Genomics and Epigenomics at the German Center for Neurodegenerative Diseases and the \\ University of Bonn, Bonn, Germany. ${ }^{3}$ Cenomics and Immunoregulation, LIMES Institute, University of Bonn, Bonn, Germany.
}

\begin{abstract}
Immune cells are pivotal in the reaction to injury, whereupon, under ideal conditions, repair and resolution phases restore homeostasis following initial acute inflammation. Immune cell activation and reprogramming require transcriptional changes that can only be initiated if epigenetic alterations occur. Recently, accelerated deciphering of epigenetic mechanisms has extended knowledge of epigenetic regulation, including long-distance chromatin remodeling, DNA methylation, posttranslational histone modifications, and involvement of small and long noncoding RNAs. Epigenetic changes have been linked to aspects of immune cell development, activation, and differentiation. Furthermore, genome-wide epigenetic landscapes have been established for some immune cells, including tissue-resident macrophages, and blood-derived cells including T cells. The epigenetic mechanisms underlying developmental steps from hematopoietic stem cells to fully differentiated immune cells led to development of epigenetic technologies and insights into general rules of epigenetic regulation. Compared with more advanced research areas, epigenetic reprogramming of immune cells in injury remains in its infancy. While the early epigenetic mechanisms supporting activation of the immune response to injury have been studied, less is known about resolution and repair phases and cell type-specific changes. We review prominent recent findings concerning injury-mediated epigenetic reprogramming, particularly in stroke and myocardial infarction. Lastly, we illustrate how single-cell technologies will be crucial to understanding epigenetic reprogramming in the complex sequential processes following injury.
\end{abstract}

\section{Introduction}

From a holistic view, the immune system is not only responsible for discrimination of self and nonself, but is critically involved in regulating physiological processes throughout the body, including tissue repair and resolution following injury (1), a term encompassing mechanical damage, exposure to toxins, temperature fluctuations, emotional stress, and dramatic changes in diet. Immediately following injury, immune cells sense the perturbation and relay local and systemic signals to other parts of the immune system (e.g., via cytokines) to induce appropriate and injury-adapted effector responses. As a final step, the immune system regulates and monitors repair and resolution of the threat, thereby reestablishing homeostasis (Figure 1). These highly integrated processes, particularly during acute phases following injury, are often described as inflammation; yet, if the endpoint is not resolution, ongoing inflammation fosters chronic low-grade inflammatory conditions, fibrosis, or abscess formation leading to diseases instead of homeostasis (2-5). An emerging picture indicates fast epigenetic regulatory mechanisms as critical activators of immune cells involved in early responses to injury $(6,7)$. However, much less is known about epigenetic reprogramming of immune cells during later phases, particularly during repair and resolution.

Authorship note: All authors contributed equally to this work. Conflict of interest: JLS received funding within research collaborations on single-cell genomics in lung diseases from Medlmmune and Boehringer Ingelheim.

Copyright: (c) 2019, American Society for Clinical Investigation.

Reference information: J Clin Invest. 2019;129(8):2994-3005.

https://doi.org/10.1172/JCl124619.
Here, we focus on recent findings concerning epigenetic mechanisms involved in regulatory immune processes during the later phases of the injury response.

\section{Epigenetic reprogramming during immune cell activation}

"Epigenetics" was first coined in 1942 by C.H. Waddington (8), but only in 2008 at a Cold Spring Harbor meeting did the scientific community agree on the definition: "An epigenetic trait is a stably heritable phenotype resulting from changes in a chromosome without alterations in the DNA sequence" (9). Today, epigenetic mechanisms are loosely understood and usually refer to DNA methylation, histone modifications, noncoding RNAs (ncRNAs), and chromatin accessibility and looping.

Chromatin structure allows (when "open") or prevents (when "closed") binding of transcriptional machinery to a DNA segment, consequently activating or silencing gene expression (Figure 2A). Chromatin accessibility is therefore used to define gene regulatory elements such as enhancers, promoters, and silencers. Various histone modifications are enriched at these sites. In general, histone acetylation is found on regulatory elements of active genes, whereas $\mathrm{H} 3 \mathrm{~K} 27$ trimethylation $(\mathrm{H} 3 \mathrm{~K} 27 \mathrm{me} 3)$ characterizes regulatory elements of silenced genes (10). H3K4 methylation (H3K4me) is widely regarded as a mark of transcriptional activity but, depending on location and crosstalk with other epigenetic modifications, can also mark nonexpressed genes; e.g., the presence of both $\mathrm{H} 3 \mathrm{~K} 27 \mathrm{me} 3$ and $\mathrm{H} 3 \mathrm{~K} 4 \mathrm{me}$ marks regulatory elements of genes that are not expressed but are readily induced upon stimulation, therefore "poised" for expression (11-13). While promoters are enriched 


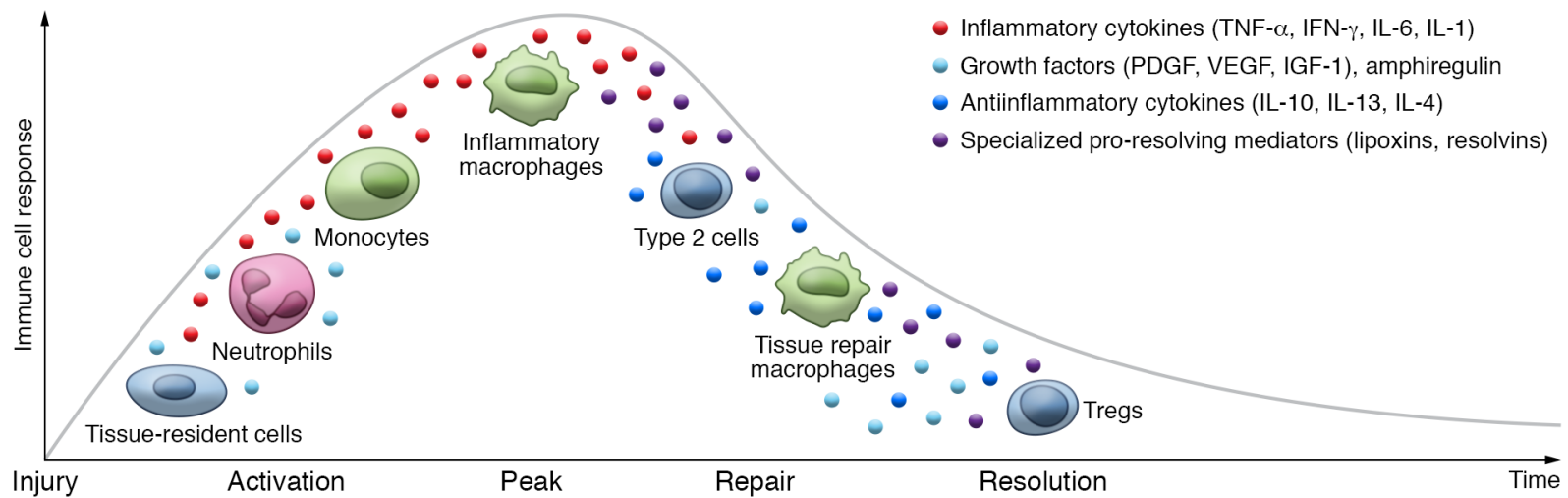

Figure 1. Immune cell activation during different phases upon tissue injury. Tissue-resident immune cells, particularly $\gamma \delta \mathrm{T}$ cells or resident macrophages, recognize damaged cells upon injury, e.g., via the NKC2D receptor or TLRs, respectively. Activated tissue-resident cells secrete soluble factors that attract other immune cells, such as proinflammatory cytokines (TNF- $\alpha$, IFN- $\gamma$, IL-6, or IL-1) together with growth factors (PDGF, VEGF, or IGF-1) that stimulate epithelial cell proliferation. CXCL8 released by tissue-resident cells in response to TLR activation attracts neutrophils, which enter the site of injury. Neutrophils produce antimicrobial molecules, cytokines, and growth factors such as VEGF-A, which recruits other inflammatory cells such as monocytes and stimulates angiogenesis and tissue cell proliferation. Recruited phagocytes clean damaged tissue debris by phagocytosis and secrete various cytokines, proteases, and growth factors promoting tissue repair. They first acquire proinflammatory function [classically activated, or M(IFN- $\gamma$ ), macrophages] and, when the pathogen is cleared, can be repolarized toward antiinflammatory tissue repair [alternatively activated, or M(IL-4), macrophages] in the presence of cytokines produced by type 2 immune T cells. M(IL-4) macrophages secrete arginase; the growth factors VEGF-A, PDGF, and IGF; and other molecules. In the resolution phase, regulatory T cells suppress immune response by secreting IL-10 and TCF- $\beta$. Further, lipid-derived specialized pro-resolving mediators actively promote inflammation cessation, resolution, and repair.

in H3K4me3, enhancers carry H3K4me1 (14). Histone modifications can affect chromatin compaction or recruit transcriptional regulators. Next-generation sequencing-based techniques such as DNase I hypersensitivity assay followed by sequencing (DNaseSeq; refs. 15, 16), assay for transposase-associable chromatin using sequencing (ATAC-Seq; ref. 17), and ChIP followed by sequencing (ChIP-Seq; ref. 18) enable investigation of chromatin accessibility and histone modification distribution at a genome-wide and single-cell level. These technological advances hugely impacted studies mapping and deciphering the role of DNA-associated proteins and accessible DNA regions in many cell types and diseases.

Initial evidence that external stimuli influence immune cell chromatin came from studies of $\mathrm{T}$ cell activation $(19,20)$, revealing the extremely compact chromatin in naive $\mathrm{T}$ lymphocytes accompanying their low-level gene expression. Antigenic encounter induces increased nuclear volume, recruitment of chromatin remodeling complexes to DNA, appearance of loose chromatin, and activation of thousands of genes, including IL2 (19-21). Altered histone modification patterns consistently accompany activation processes of various immune cells. Genes induced during transition from naive to germinal center $\mathrm{B}$ cells gain activating histone marks such as $\mathrm{H} 3 \mathrm{~K} 4 \mathrm{me}$ and $\mathrm{H} 3 \mathrm{ac}$, while silenced loci lose these marks (22). Similarly, H3K4me and histone acetylation are increased in effector and memory $\mathrm{T}$ cells at loci linked to genes induced upon activation of naive $\mathrm{CD}^{+}(23-26)$ and $\mathrm{CD}^{+} \mathrm{T}$ cells (27). Conversely, genes that become downregulated in effector $\mathrm{CD}^{+} \mathrm{T}$ cells lose activating histone marks and gain suppressive H3K27me3 at adjacent loci $(25,26,28)$. Naive immune cell activation also causes changes in chromatin accessibility that largely correlate with changes in gene expression (29-36). Yet exceptions exist, exemplified by Fasl and Prf1, which are highly inducible upon $\mathrm{CD}^{+} \mathrm{T}$ cell activation but show no significant changes in chromatin accessibility at adjacent loci (35). Assessing the function of an open chromatin region necessitates examination of the collective view of transcription factors bound to the region and long-distance interactions. In Tregs, for instance, Foxp3 gene induction causes appearance of very few de novo enhancers, but Foxp3 binds to preexisting open sites in Foxp3 ${ }^{-} \mathrm{CD}^{+}{ }^{+} \mathrm{T}$ cells, exemplifying the importance of enhancer usage by transcription factors (37). LPS stimulation of macrophages induces a tolerance program that silences proinflammatory genes, including IL6. However, antimicrobial genes like CNLP remain inducible (38). Distinct chromatin accessibility and histone modification patterns on both classes of genes determine their readiness to be re-expressed. TLR4 engagement precedes the appearance of H3K4me1, H3K4me2, and H3K27ac peaks at de novo (or latent) enhancers; these are maintained and enable enhanced expression of target genes upon secondary stimulation (39-41). Interestingly, the tissue environment also shapes a specific chromatin signature in tissue-resident macrophages (42).

Regulatory elements can be located far upstream of a gene's transcriptional start site and must be brought into physical proximity with the gene promoter by chromatin looping to impact gene expression. Interaction between regulatory elements is believed to facilitate the recruitment of transcriptional machinery; hence chromatin looping is another epigenetic mechanism regulating gene expression (43). A classic example of such regulation within the immune system is the recombination of antigen receptorcoding genes (44). Furthermore, chromatin looping regulates expression of various cytokines in activated T cells, e.g., the type 2 cytokine locus comprising Il4, Il5, and $I l 13(45,46)$, as well as Ifng (32), Tnfa (47), and Il21 (48). Likewise, LPS stimulation of macrophages induces DNA loops at the IL1/IL36/IL37 gene cluster (49) or osteopontin (Spp1) locus (50). More recent genome-wide studies of chromatin conformation in hematopoietic cells revealed cell type-specific interactome signatures (51-53); hence processes including monocyte differentiation toward macrophages (54), B 
A

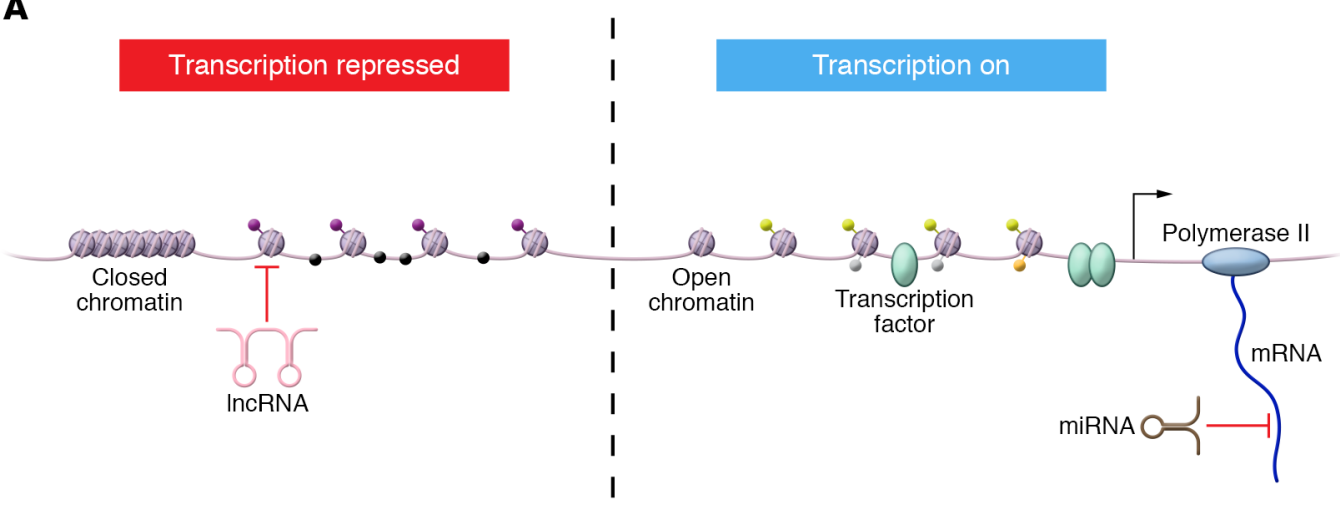

B

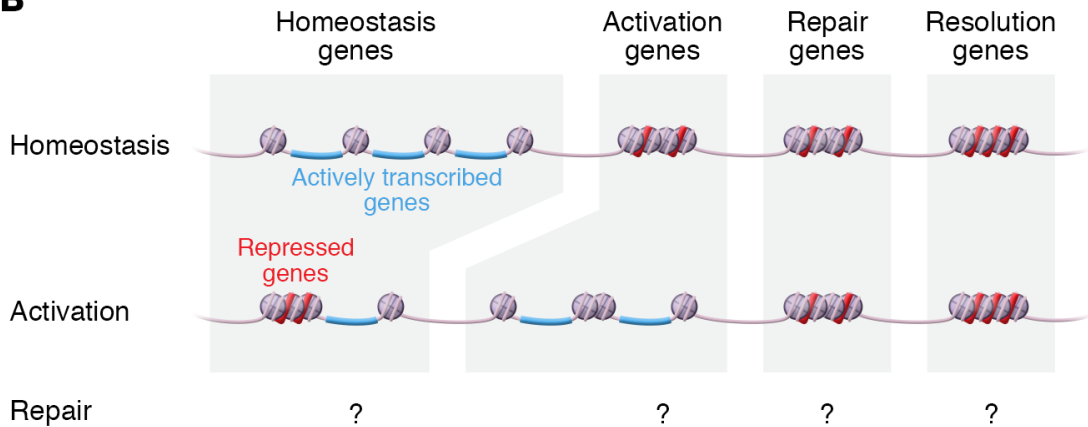

Epigenetic regulation during repair and resolution mainly unknown

Resolution
$?$
$?$

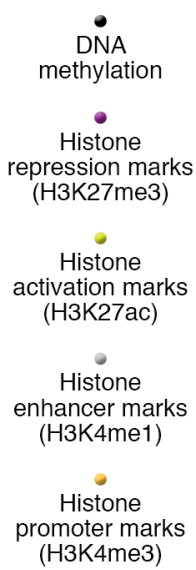

DNA

epression marks

(H3K27me3)

Histone

ctivation marks

○

Histone

(H3K4me1)

Histone

(H3K4me3)

Figure 2. Epigenetic events in immune cells during tissue injury. (A) Possible modes of epigenetic regulation to tune immune cell function. On the left, mechanisms of repressing transcription such as closed chromatin, DNA methylation, repressive histone marks, or inhibiting long noncoding RNAs (IncRNAs) are depicted. On the right, a locus with active transcription is depicted, including loss of DNA methylation, open chromatin structure including accessible enhancer and promoter sequences, activating histone modifications, and activating transcription factors. Different histone marks are presented as colored dots. (B) During immune cell activation, epigenetic regulation leads to activation of prior silent genes, while some homeostatic genes are turned off. Epigenetic events during homeostasis and activation of immune cells have been experimentally addressed, while elucidation of these processes during repair and resolution still needs to be resolved.

cell activation $(29,55)$, and $\mathrm{T}$ cell development $(56)$ and differentiation (57) are accompanied by genome-wide reorganization of chromatin loops. Much remains unknown about chromatin interaction dynamics in different biological processes, including injury. New technologies are emerging to address these questions, including high-throughput chromosome conformation capture (HiC; ref. 58), next-generation Capture-C (NG Capture-C; ref. 59), chromatin interaction analysis by paired-end tag sequencing (ChIA-PET; ref. 60), protein-centric chromatin conformation method (Hi-ChIP; ref. 61), and transposase-mediated analysis of chromatin looping (Trac-looping; ref. 62).

DNA methylation (the presence of 5-methylcytosine [5mC]), which in vertebrates affects mainly palindromic CpG sites, can also change a gene transcription, e.g., by affecting binding of methylation-sensitive transcription factors $(63,64)$. It is broadly accepted that DNA methylation is a suppressive mark, yet its role is still not fully understood. Depending on its location within the genome, tissue-specific distribution, and cellular context, it mediates transcriptional repression but has also been linked to gene activation (65). For example, "atypical" promoters enriched in $5 \mathrm{mC}$ and $\mathrm{H} 3 \mathrm{~K} 4 \mathrm{me} 3$ but driving transcription were found in germline cells (66). Similarly, global hypomethylation does not induce genome-wide activation of transcriptome in primordial germ cells (67). DNA methylation can also occur in non-CpG context $(5 \mathrm{mCH}$, where $\mathrm{H}$ represents $\mathrm{A}, \mathrm{C}$, or $\mathrm{T})$ in almost all human tissues (68-70). $5 \mathrm{mCH}$ is present in globally high levels in naive T cells (71), yet its function is largely unknown. For decades, DNA methylation was considered a very stable modification. With the discovery of ten-eleven translocation (TET) DNA dioxygenases, which actively remove methyl groups from $\mathrm{CpG}$ sites by converting $5 \mathrm{mC}$ to 5-hydroxymethylcytosine (72) and further to 5-formylcytosine and 5 -carboxycytosine $(73,74)$, and the recent development of next-generation sequencing-based technologies allowing genome-wide studies of DNA methylation at the single-cell level, it emerged that the DNA methylation fingerprint is reversible and dynamic (75). DNA methylation's important role in immune cell development and activation (76) makes it a potential therapeutic target for treatment of inflammation-driven diseases. Deleting or pharmacologically inhibiting DNA methyltransferases (DNMTs) using 5-aza-2'-deoxycytidine decreases inflammation in models of atherosclerosis and obesity (77-79). DNMT3B targets the promoter of PPARG, a key transcription factor for alternative acti- 


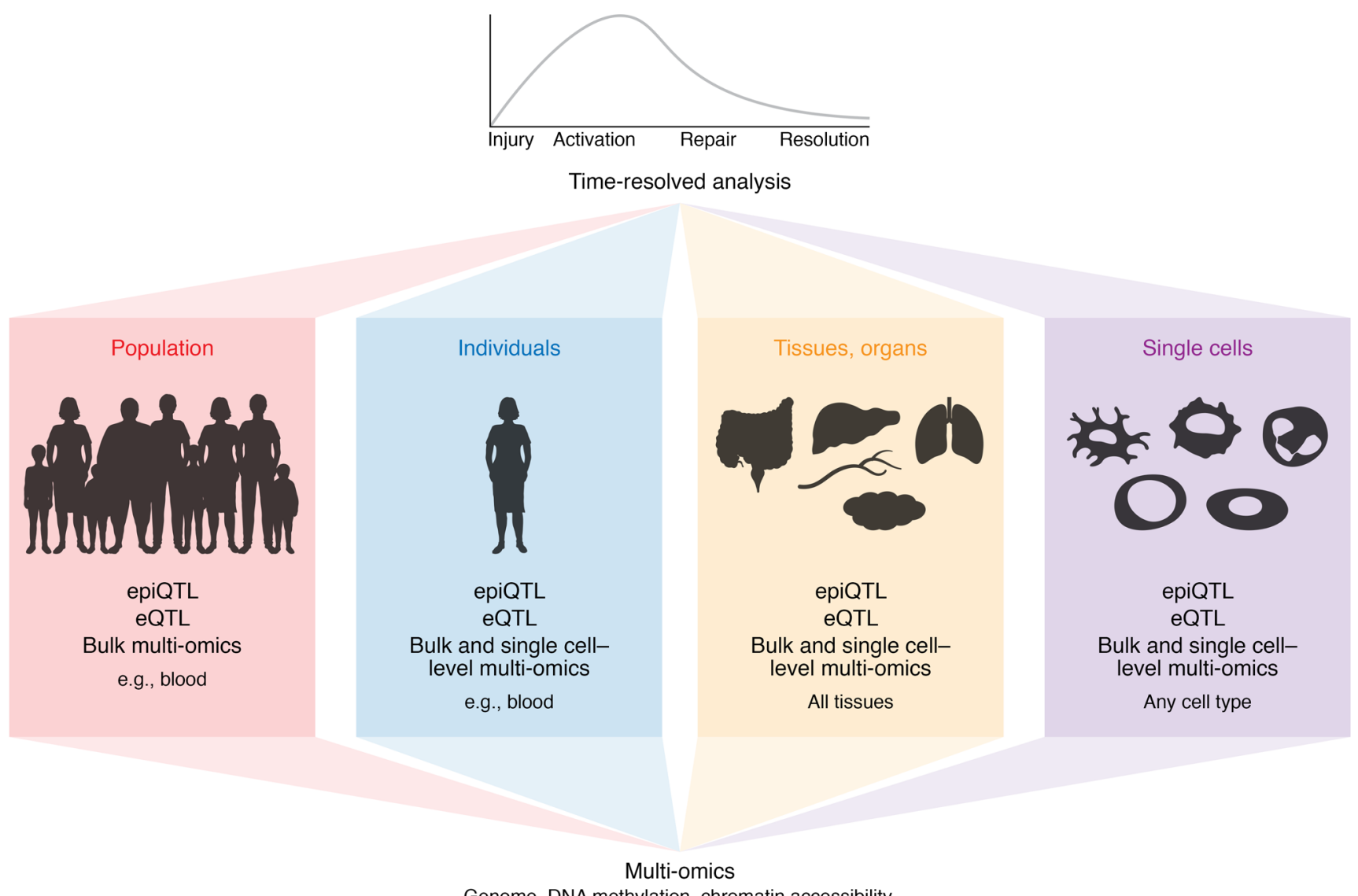

Genome, DNA methylation, chromatin accessibility,

histone modifications, ncRNAs, mRNA, proteome, metabolome

Figure 3. Integrated view of the epigenetic processes occurring over time during injury, repair, and resolution. Epigenetic regulatory mechanisms can be studied on the level of population, individual, and tissues and organs, as well as the single-cell level. Since any injury is followed by a sequence of processes ranging from immune system activation to peak reactivity to repair and resolution, time-resolved analyses of epigenetic processes are required. At the different levels (population, individuals, tissues and organs, and single cells), different multi-omics approaches can be applied to determine epigenetic regulation. Resolution, complexity that can be determined, scalability of epigenetic assays, and costs of analyses differ substantially between the different settings. Future studies particularly targeting the repair and resolution phases will require sophisticated planning of overall goals and experiments to be performed. eQTL, expression quantitative trait loci; epiQTL, epigenetic quantitative trait loci.

vation of macrophages, leading to PPARG suppression and thus a cellular proinflammatory state (79). Similarly, TET deficiency drives increased IL-6 and IL-1B expression in activated macrophages, which leads to impaired resolution of inflammation (8083), suggesting a role of DNA methylation in macrophage activation. Transition from naive $\mathrm{B}$ and $\mathrm{T}$ cells to effector and memory cells also involves DNA methylation as loci responsible for effector functions progressively lose this mark (84-88). Furthermore, in $\gamma \delta \mathrm{T}$ cells, DNA methylation status of the Ifng locus controls the ability to produce high amounts of IFN- $\gamma$ (89), whereas in Tregs, it plays a crucial role in maintaining cell identity by regulating Foxp3 expression necessary for Treg development and function (90).

ncRNAs belong to a still-growing list of newly recognized gene regulators. These regulatory RNAs are not translated into proteins, range in size, are transcribed from different genomic locations, and hold a variety of functions. Based on these characteristics, they are segregated into different classes $(91,92)$. The best-characterized class of ncRNAs are short ( $<200 \mathrm{bp}$ ) microRNAs (miRNAs) that silence gene expression by either inducing degradation of target mRNA or blocking its translation (93-95). Long noncoding RNA (lncRNA; >200 bp) can also silence gene expression at the transcriptional level by affecting chromatin structure (92). This is achieved by directing de novo DNA methylation (96) or histone modification patterns (97), or mediating chromatin looping (98).

Immune cell differentiation and activation are accompanied by huge changes in ncRNA expression (99-101); e.g., TLR2 stimulation of macrophages induces the long intergenic ncRNA lincRNA-Cox2, which regulates IL-6 and CCL5 expression (102), or downregulates linc1992 (or THRIL), which affects TNF- $\alpha$ expression (103). TLR4 stimulation induces high levels of lnc-IL7R, 
which activates the endothelial cell adhesion molecules VCAM-1 and E-selectin by reducing repressive $\mathrm{H} 3 \mathrm{~K} 27 \mathrm{me} 3$ promoter marks (104). NeST ncRNA interacts with the WDR5 subunit of histone H3K4 methylating complexes and induces IFN- $\gamma$ expression by modifying chromatin at IFN- $\gamma^{\prime}$ s gene locus in $\mathrm{CD}^{+} \mathrm{T}$ cells (105). In $\mathrm{CD}^{+}{ }^{+} \mathrm{T}$ cells, lincR-Ccr-5'AS is important for Th2 cell migration to the lung (100). Although ncRNAs are very abundant, their role during immune responses is only beginning to be understood.

Once acquired, epigenetic changes persist throughout cell divisions, enabling the maintenance of cell identity (106). However, responsiveness to environmental cues and reversibility of epigenetic landscapes permit plasticity in transcriptional programs of already differentiated cells. These features position epigenetic mechanisms as ideal molecular instruments for controlling immune cell activity, which must remain specialized in function but able to adjust response according to various environmental exposures. Unsurprisingly, genome-wide changes in DNA methylation, histone modifications, chromatin accessibility, ncRNA expression, and long-range chromatin interactions accompany immune cell development throughout hematopoiesis $(56,107,108)$ as well as activation. While the role of epigenetics during development, differentiation, and activation is well accepted (Figure 2B), much less is known regarding the resolution and repair phase of immune responses, for which we will highlight some recent findings in cells of the innate and adaptive immune systems.

\section{Epigenetic reprogramming in innate immune cells during injury}

Tissue injury sensed by the immune system produces a concerted action of different immune cells. Tissue-resident immune cells are first responders to the insult, inducing proinflammatory signals to attract further circulating immune cells, such as monocytes and neutrophils. When the insult is cleared, inflammation must be counteracted, proinflammatory cells eliminated, further leukocyte recruitment abrogated, and tissue repair mechanisms supported actions facilitated by specialized pro-resolving mediators (SPMs) that act on immune cells and surrounding tissues to restore homeostasis (109). Failed resolution of damage and the associated acute inflammatory reaction lead to abscess formation, fibrosis, or chronic low-grade inflammation and consequently further tissue damage (110). Macrophages not only initiate immune reactions in response to injury, but are equally important for their resolution, e.g., via production of antiinflammatory SPMs (111). While the epigenomic landscape of different immune cells and subsets under homeostasis and their changes following activation are well studied, the molecular determinants of the retraction phase leading to resolution and repair are less explored. As tissue-resident macrophages critically impact local homeostasis $(112,113)$, signals present in their microenvironment, such as metabolites, mechanical signals, apoptotic bodies, and cytokines, prime distinct transcriptional and epigenomic programs in different tissues, thereby imparting specific responses to danger signals (42, 113-116). For example, an NaCl-rich environment alters $\mathrm{H} 3 \mathrm{~K} 4 \mathrm{me} 3$ at multiple loci in macrophages, promoting a proinflammatory phenotype by facilitating increased NO release upon LPS stimulation (117), as well as a decreased antiinflammatory phenotype through silencing of the Il4 and Il13 loci (118) - collectively delaying wound repair under high-salt conditions.
Stroke is one example of tissue injury for which the impact of epigenetic regulation is already addressed (119). Dynamic global changes in DNA methylation are associated with atherosclerosis progression (120) and stroke outcome (121). More specifically, studies have linked stroke incidence or outcome to the regulation of genes involved in platelet conglomeration (TRAF, PPM1A; refs. $122,123)$; cell adhesion and thereby leukocyte recruitment during acute inflammation (LINE-1; ref. 124); and angiogenesis induction during repair (THBS1; refs. 125-128). Yet, contradictory reports concerning DNA methylation's impact in different stroke subtypes indicate a need for more in-depth analysis of different pathological settings, discrimination of epigenetic changes on the gene level, and, more importantly, study of cell type-specific alterations (119). As histone $\mathrm{H} 3$ acetylation is greatly reduced upon ischemic stroke, many studies found that inhibition of histone deacetylation was favorable for stroke outcome: it suppressed microglia activation, induced neuroprotective proteins (e.g., IGF-1 or Hsp70), and favored functional recovery (reviewed in ref. 119). Albeit encouraging, detailed knowledge concerning the influence of the different histone deacetylase (HDAC) inhibitors on different members of the HDAC family and their specific effects in different cell types remains incomplete.

Similarly, histone methylation status and transcriptome regulation by differential miRNA production have been addressed in the context of stroke. While some altered epigenetic marks were generally described, studies have not yet addressed immune cells in particular, as descriptions remain on the tissue level (119). Recent results from the miRNA field address this issue; e.g., miR-155 and miR-210 induce a proinflammatory signature in microglia (129), and a miR-155 antagomir proved neuroprotective by reducing inflammation and infarct size in a mouse model for ischemic stroke (130). Conversely, miR-let-7a downregulates proinflammatory IL- 6 and iNOS and upregulates factors involved in counteracting inflammation and supporting resolution, e.g., IL-4, IL-10, and brain-derived neurotrophic factor (BDNF) (131). In fact, many miRNAs have been identified as regulating transcriptional programs during the different phases of acute inflammation, resolution, and repair upon injury (132).

Aside from ischemic insult in stroke, epigenetic regulation of immune cells throughout injury has been addressed in several other settings: A global increase in DNMT1 expression and DNA methylation in PBMCs was suggested as a biomarker for screening individuals at risk of developing Alzheimer's disease (133). During lung inflammation, cardiolipin induced HDAC3-mediated deacetylation of the Il1O promoter, thereby inhibiting resolution (134). A similar role was noted in atherosclerosis, in which HDAC3 is upregulated in macrophages from ruptured atherosclerotic lesions and associated with inflammatory macrophages (135). Analysis of myeloid-specific Hdac3-knockout mice revealed this deacetylase as a positive regulator of arterial inflammation: deficient mice showed plaque stabilization resulting from reduced lipid accumulation and increased fibrosis via TGF- $\beta$ in an atherosclerosis model (135). Resolution of arthritis is promoted by HDAC2's interaction with Tet2, leading to deacetylation and thus repression of the Il6 locus (82). HDAC3 inhibition also proved beneficial in spinal cord injury (136). 
General targeting of DNA methylation or histone acetylation may pose risk for adverse effects due to systemic modulation of immune cell function and effects on other cell types. Targeting miRNAs that regulate a narrower subset of genes appears to be a more concise approach, though the pharmacokinetic properties of miRNA agonists remain challenging and are currently being addressed. Collectively, cell type-specific spatial and temporal clarifications of molecular processes and determinants of the inflammatory cascade upon injury are crucial for developing novel therapies, particularly when targeting epigenetic mechanisms.

Epigenetic modifications in macrophages remain on the verge of being unraveled. Their changes in the context of ontogeny and the influence of environment under homeostasis demonstrate their ample plasticity $(112,113)$. In contrast to simplistic monovalent in vitro stimulations, a future challenge will be integrating the effects of simultaneous exposure to all signals present in the tissue (114). Exploring spatial and temporal features of cell typespecific epigenetic mechanisms during injury will be necessary to elucidate regulatory mechanisms in the involved cell types. Albeit technically challenging, the continuous fast-paced progress in epigenomic techniques will enable these kinds of studies soon.

Resolution of the acute inflammatory reaction upon injury involves a plethora of soluble mediators within the affected tissue microenvironment as well as many different cell types whose capacity to respond to these mediators determines the outcome. Deciphering the layers of epigenetic regulation acting on responsive receptors, signaling cascades, and effectors will be valuable for identifying repair-promoting therapies.

Since single-cell RNA sequencing (scRNA-Seq) methods became available, the elucidation of heterogeneity within different tissue-resident immune cell populations has become a lively field of investigation. Understanding of mechanisms at play during injury, documentation of the different immune cells present, and distinguishing of subsets (e.g., resident vs. infiltrating myeloid cells) are pivotal. Notably, changes in the tissue microenvironment during injury diversify the immune cell populations present: infiltrating cells may acquire markers of tissue-resident cells, and detailed knowledge of immune cell populations present during homeostasis and injury will be necessary to address ongoing changes during this pathological process. Proper stratification is necessary to address the different contributions of different subpopulations to injury, particularly with regard to tissue repair, as well as to study underlying molecular mechanisms such as epigenetic modifications.

\section{Epigenetic reprogramming of lymphocytes during injury}

Although less is understood about the role of epigenetic mechanisms within lymphocytes during later phases of injury, particularly the repair and resolution phases, lymphocytes' roles during wound healing are well appreciated $(137,138)$. T cells are clearly present at sites of injury (139-141), and depending on the tissue and $\mathrm{T}$ cell subsets, they can have positive or negative effects on tissue regeneration. Generally, $\gamma \delta \mathrm{T}$ cells, innate-like lymphocytes (ILCs), and Tregs positively influence tissue repair, while helper and cytotoxic T cells can delay fracture healing by secreting IFN- $\gamma$ and TNF- $\alpha$ cytokines, which inhibit osteogenesis $(142,143)$. On the other hand, recent studies show a protective role of $\mathrm{T}$ cells in CNS injury (144), acute kidney injury (145), myocardial infarction (146), and muscle repair (137). Type $1 \mathrm{~T}$ helper (Th1) cells promote inflammation, whereas Th2 cells have antiinflammatory effects and contribute to recovery from injury. Differentiation of naive $\mathrm{T}$ cells toward these subsets requires $\mathrm{T}$ cell receptor engagement followed by epigenetic mechanisms. Effector cells deficient in the H3K27me3 methyltransferase EZH2 do not protect from Toxoplasma gondii infection and can drive autoimmune colitis (147). Conversely, during renal or bone marrow transplantation, EZH2 inhibition ameliorates allograft rejection and reduces injury by suppressing cytokine production and inducing alloreactive $\mathrm{T}$ cell apoptosis $(148,149)$. It remains unclear which receptors are involved in injury-induced $\mathrm{T}$ cell activation, especially during sterile inflammation such as ischemia wherein cognate antigen is absent. T cell activation at injury sites unlikely resembles naive $\mathrm{T}$ cell differentiation or encompasses similar epigenetic changes, which has started to be addressed only recently (150). Cytotoxic Tc17 and helper Th17 cells induced by Staphylococcus epidermidis fight the infection by producing IL-17 but also possess wound healing potential due to their poised type 2 immunity program. They have the capacity to produce high levels of the type 2 cytokines IL-5 and IL-13, as they hold opened chromatin for these gene loci and low levels of the corresponding transcripts (150). Collectively, Tc17 cells generated during S. epidermidis colonization improve skin wound healing in an IL-13-dependent manner (150). It is therefore possible that $\mathrm{T}$ cells, especially tissue-resident ones, acquire poised epigenetic signatures upon encounter with an antigen, allowing for the appropriate cytokine production upon injury.

$\gamma \delta \mathrm{T}$ cells constitute a major lymphocyte population in mucosal tissues and skin. Upon cutaneous damage, they are one of the first cellular components mobilized in response to stress signals, secreting soluble factors that attract further inflammatory cells but also directly stimulating epithelial cell proliferation by mitogens such as the keratinocyte growth factors IGF-1 (151), FGF-7, and FGF-10 $(152,153)$. Lung-resident $\gamma \delta$ T cells produce IL-22, which prevents fibrosis (154), and $\gamma \delta$ T cells in bone secrete IL-17A, accelerating osteogenesis during fracture healing (155). Whether $\gamma \delta$ T cells produce IFN- $\gamma$ or IL-17 is largely decided during thymic development. Very few $\gamma \delta$ T cells leave the thymus as non-pre-programmed cells with the potential to be instructed by peripheral environmental cues (156). The capability to produce either IFN- $\gamma$ or IL-17A, IL-17F, and IL-22 is encoded in the chromatin structure. IFN- $\gamma$-producing $\mathrm{CD} 27^{+} \gamma \delta \mathrm{T}$ cells show enrichment of suppressive H3K27me3 marks at the Il17a, Il17f, and Il22 loci and enrichment of $\mathrm{H} 3 \mathrm{~K} 4 \mathrm{me} 2$ at the Ifng locus, while IL-17-producing $\mathrm{CD}^{-} \gamma \delta \mathrm{T}$ cells possess $I l 17 a$, Il17f, and Il22 loci in a poised state with H3K27me3 and H3K4me2 present (157). Although one may conclude that epigenetic reprogramming of $\gamma \delta \mathrm{T}$ cells in the periphery is limited, regulating $\gamma \delta \mathrm{T}$ cell function during injury can still be an important process that needs further investigation in a spatiotemporal fashion during all phases of injury to better understand the role of these important immune cells during injury.

Uncontrolled inflammation after tissue damage can impair tissue healing and regeneration, as happens in chronic ischemic heart failure $(158,159)$. Tregs at the injury site can ease resolution of inflammation by facilitating repair of many tissues, including bone 
(142), skin (160), lungs $(161,162)$, kidney $(163,164)$, CNS $(165)$, and skeletal (141) and cardiac muscles (166). During injury, Tregs modulate neutrophil behavior (161), influence monocyte/macrophage activation toward an antiinflammatory phenotype (167), and reduce lymphocyte production of the proinflammatory cytokines TNF- $\alpha$ and IFN- $\gamma$ (142). Tregs can also directly affect wound healing by producing growth factors such as amphiregulin (141), which promotes tissue regeneration. Because DNA methylation plays an important role in regulating Foxp3 expression, it may also affect tissue repair and resolution processes. Indeed, the DNMT inhibitor 5-aza-29deoxycytidine (DAC) accelerates resolution of experimental lung injury at least partially via a salutary effect on Tregs. DAC treatment increases Treg numbers and function in the wounded lung (168). Clearly, further work is necessary to precisely understand which epigenetic mechanisms operate in Tregs and therefore might be targeted therapeutically to foster tissue repair and resolution.

Presence of ILCs also appears beneficial for restoring tissue homeostasis after injury (169). Depletion of type 2 ILCs, which are responsive to IL-33, impaired wound healing in the lung after influenza infection (170) and in corneal tissues after corneal epithelial abrasion (171). ILCs acquire specific chromatin modifications during development, rendering stimulation-inducible genes poised for expression. Neither in vitro nor in vivo stimulation seems to affect chromatin accessibility in ILCs $(172,173)$. However, the microbiome influences the epigenetic landscape of different ILC subgroups (173). Clearly, the role of epigenetic changes within individual ILC populations in response to tissue damage remains to be determined.

Collectively, while the role of lymphocytes during injury is becoming more explicit, the epigenetic events occurring during later phases of the immune response to tissue damage are largely unknown, particularly regarding epigenetic reprogramming of lymphocytes. Based on the few data available, it is tempting to speculate that cells involved in tissue repair including $\gamma \delta \mathrm{T}$ cells, Tc17 cells, and ILCs acquire their healing potential through reprogramming at the chromatin level before the injury happens. It is also critical to address the role of epigenetic mechanisms during the late repair and resolution phases. First attempts to look into the role of epigenetics in this process remain very limited. Although epigenetic inhibitors have already been tested as potential strategies for improving wound healing processes $(148,149,174)$, a better understanding of epigenetic events involved in tissue repair is necessary to develop precision medicine strategies.

\section{Integrated view on injury including repair and resolution}

During the body's reaction toward an injury, immune cells act in a system-like fashion, involving many different immune cell types throughout the process $(3,175,176)$. Different dimensions of interactions must be considered. On the population level, genetic variation can impact molecular mechanisms involved in repair and resolution processes (Figure 3). In this context, the analysis of quantitative trait loci (QTL), particularly expression QTL and epigenetic QTL, can shed light on an individual's genetic and environmental susceptibility to dysregulation in different phases of the injury response (177). Furthermore, each individual's exposure to a myriad of environmental stimuli throughout life results in epi- genetic modifications that add another important layer on top of the genetic code explaining disease susceptibility and outcome. Because every immune cell type reacts in a time-resolved fashion during the different phases after injury, single-cell technologies that define transcriptional and epigenetic changes are becoming more and more important (178-180). Furthermore, because epigenetic regulation occurs on several levels, multi-omics approaches are required to simultaneously interrogate major regulatory epigenetic and transcriptional mechanisms during injury, repair, and resolution (Figure 3 and refs. 181, 182). So far, single-cell methods such as scATAC-Seq (183), scDNase-Seq (184), and scMNase-Seq (185) have not been applied to address the processes during repair and resolution of injuries. Unsurprisingly, we are far from being able to assess population, individual, organ, tissue, single cells, time, and multi-omics dimensions to develop an integrated view of the pathological processes.

Using myocardial infarction (MI) as a very prominent example of injury, as the world's leading cause of death (186), we will now illustrate how an integrated view might be envisioned for future research. Recent work has clearly established the interplay between local immune cells, particularly myocardial tissue macrophages, and immigrating immune cells such as neutrophils and monocytes during MI (175). On the genetic level, over 50 loci identified in the last decade are associated with increased risk for coronary artery disease (CAD) and MI (187). The large majority of these loci are located in noncoding parts of the genome, making epigenetic regulation of transcription rather than protein structure more likely to be influenced. A very prominent susceptibility locus for CAD/MI at chromosome 9p21 was initially linked to the two closest protein-coding genes, CDKN2A and CDKN2B (188). However, more recent studies illustrate the requirement to infer causality from genetic variation studies (189-191). It is now established that the risk and nonrisk alleles at this locus code for different isoforms of the lncRNA ANRIL, resulting in differential epigenetic functionality of this lncRNA and ultimately modulating the expression of multiple genes (192).

Several epigenetic mechanisms, including DNA methylation and histone modifications, are linked to aberrant cardiac wound healing $(193,194)$, although current knowledge is mostly based on studies assessing epigenetic changes on the tissue level rather than the cell type level. For example, patients with end-stage heart failure show global reduction of DNA methylation in $\mathrm{CpG}$ islands, and some of these epigenetic changes are associated with dysregulated expression of genes implicated in angiogenesis (195). Similarly, alterations in histone methylation were observed in human heart failure (196), yet these studies do not address epigenetic changes in individual immune cell subsets involved in heart injuries. Indeed, very little is known about epigenetic changes in immune cell subsets during heart failure or other heart injuries. Treating rats with the DNMT inhibitor 5-azacytidine reduced macrophage number after MI, and the remaining macrophages had a more antiinflammatory phenotype (197). Histone modifications are implicated in macrophage reprogramming $(114,198)$ but have not been studied in great detail in the context of MI or other heart injuries in vivo, certainly not in an integrated fashion at the cell type or even the single-cell level. A comparison of the transcriptional regula- 
tion of repair mechanisms within adult and neonatal mammalian hearts suggested that both adult and neonatal immune cell compartments express a proliferative gene expression network following MI. In contrast, adult cardiomyocytes are unable to reactivate the network of proliferative genes expressed in neonatal cardiomyocytes following MI (199). An integrated view on transcriptional regulation and genome-wide chromatin accessibility landscapes in cardiomyocytes after MI reveals that loci required for entering the cell cycle are characterized by a closed chromatin landscape. This allows neonatal cells to repair MI without leading to scar formation, which is the major option for resolving the injury in adults. While this study reveals important epigenetic and transcriptional regulatory mechanisms influencing post-MI repair and resolution mechanisms on the cell type level, we must consider further heterogeneity within individual cell types during all phases of injury. scRNA-Seq technologies are well suited to address such heterogeneity, even in a spatiotemporal fashion $(179,180)$. Applied to MI, functionally defined cellular states within the myeloid compartment are recognized in infarcted tissue (200). Combined with fate-mapping technologies, immunofluorescence studies, and temporal kinetics of individual subpopulations, a picture of differential functionality within the myeloid cell compartment during the different postMI phases evolves. The earliest phases involve functional changes in local tissue macrophages, leading to an influx of neutrophils and monocytes that promote an inflammatory reaction. These cells are replaced at later time points by subsets characterized by classical repair mechanisms $(178,200)$. Particularly surprising within these studies is the functional heterogeneity of immune cells during the different phases of an injury such as MI. Understanding these distinct functional states within the myeloid compartment allows targeting of particular subpopulations to manipulate the natural history of the disease $(180,200)$. For example, depleting resident macrophages after infarct worsens cardiac function, indicating that protecting these cells from depletion might be a potential therapeutic concept. Clearly, we must further evaluate the predicted functionality of all the newly identified functional states and link these transcriptional changes to epigenetic regulation that also might be targeted therapeutically.

\section{Outlook and summary}

Epigenetic regulatory mechanisms are very dynamic and confer numerous options for any single cell to react to changes in its microenvironment, be they homeostatic or pathophysiological. Injuries, with their different phases, require well-orchestrated epigenetic changes in all immune cells involved in the process to allow for a proper restoration of tissue homeostasis following the acute inflammation upon injury. As we have only begun to understand the many different epigenetic mechanisms that exist, it is not surprising that our picture of epigenetics' role in later phases of injuries, namely repair and resolution, remains mostly incomplete. Profound knowledge about the different tissue-resident and patrolling immune cell populations and subsets present under homeostatic conditions is a prerequisite to understand pathophysiological processes. Single-cell technologies are currently paving the way to decipher and describe immune cell populations at unprecedented levels, enabling isolation and characterization of rare cells on an epigenetic level. Technological limitations of many epigenetic assays concerning the quantity of necessary input material have prohibited detailed studies of these processes during injury. Yet we strongly believe that it will be rather rewarding to complete these studies, as the decision between tissue resolution after injury versus chronic low-grade inflammation, development of fibrosis, or generation of abscesses as second-best options is certainly affected and modulated by distinct epigenetic regulatory mechanisms. The conditions and factors present in injured tissue are influential, but it is also becoming clear that genetic variability, age, and environmental influences can leave their epigenetic mark and influence injury susceptibility and outcome. Revealing these specific epigenetic switches in defined immune cell subsets will bring us closer to targeted therapies for many of the pathophysiological conditions following injuries, and these epigenetically motivated therapies might form the basis of precision medicine for related chronic illnesses.

\section{Acknowledgments}

JLS is funded by the Deutsche Forschungsgemeinschaft (German Research Foundation) under Germany's Excellence Strategy - EXC2151 - 390873048. JLS has received funding from the European Union's Horizon 2020 research and innovation programme under grant agreement 733100 . JLS is a member of the Aging and Metabolic Programming (AMPro) consortium. KP is supported by Marie Sklodowska Curie Actions Individual Fellowship of the European Commission (798582).

Address correspondence to: Katarzyna Placek, Joachim L. Schultze, or Anna C. Aschenbrenner, LIMES Institut, Carl-Troll-Straße 31, 53115 Bonn, Germany. Phone: 49.228.73.62742; Email: kplacek@ uni-bonn.de (KP). Phone: 49.228.73.62787; Email: j.schultze@unibonn.de (JLS). Phone: 49.228.73.62792; Email: a.aschenbrenner@ uni-bonn.de (ACA).
1. Rankin LC, Artis D. Beyond host defense: emerging functions of the immune system in regulating complex tissue physiology. Cell. 2018;173(3):554-567.

2. Fahy JV. Type 2 inflammation in asthma - present in most, absent in many. Nat Rev Immunol. 2015;15(1):57-65.

3. Gieseck RL, Wilson MS, Wynn TA. Type 2 immunity in tissue repair and fibrosis. Nat Rev Immunol. 2018;18(1):62-76.

4. Buckley CD, Gilroy DW, Serhan CN, Stockinger B, Tak PP. The resolution of inflammation. Nat Rev Immunol. 2013;13(1):59-66.
5. Hotamisligil GS. Inflammation, metaflammation and immunometabolic disorders. Nature. 2017;542(7640):177-185.

6. Busslinger M, Tarakhovsky A. Epigenetic control of immunity. Cold Spring Harb Perspect Biol. 2014;6(6):a019307.

7. Phan AT, Goldrath AW, Glass CK. Metabolic and epigenetic coordination of $\mathrm{T}$ cell and macrophage immunity. Immunity. 2017;46(5):714-729.

8. Waddington $\mathrm{CH}$. The epigenotype. 1942. Int J Epidemiol. 2012;41(1):10-13.

9. Berger SL, Kouzarides T, Shiekhattar R, Shilati- fard A. An operational definition of epigenetics. Genes Dev. 2009;23(7):781-783.

10. Bannister AJ, Kouzarides T. Regulation of chromatin by histone modifications. Cell Res. 2011;21(3):381-395.

11. Bernstein BE, et al. A bivalent chromatin structure marks key developmental genes in embryonic stem cells. Cell. 2006;125(2):315-326.

12. Wei G, et al. Global mapping of H3K4me3 and $\mathrm{H} 3 \mathrm{~K} 27 \mathrm{me} 3$ reveals specificity and plasticity in lineage fate determination of differentiating CD4 ${ }^{+}$T cells. Immunity. 2009;30(1):155-167. 
13. Roh TY, Cuddapah S, Cui K, Zhao K. The genomic landscape of histone modifications in human T cells. Proc Natl Acad Sci U S A. 2006;103(43):15782-15787.

14. Heintzman ND, et al. Distinct and predictive chromatin signatures of transcriptional promoters and enhancers in the human genome. Nat Genet. 2007;39(3):311-318.

15. Crawford GE, et al. Identifying gene regulatory elements by genome-wide recovery of DNase hypersensitive sites. Proc Natl Acad Sci US A. 2004;101(4):992-997.

16. Sabo PJ, et al. Genome-wide identification of DNaseI hypersensitive sites using active chromatin sequence libraries. Proc Natl Acad Sci U S A. 2004;101(13):4537-4542.

17. Buenrostro JD, Giresi PG, Zaba LC, Chang HY, Greenleaf WJ. Transposition of native chromatin for fast and sensitive epigenomic profiling of open chromatin, DNA-binding proteins and nucleosome position. Nat Methods. 2013;10(12):1213-1218.

18. Barski A, et al. High-resolution profiling of histone methylations in the human genome. Cell. 2007;129(4):823-837.

19. Siebenlist U, et al. Promoter region of interleukin-2 gene undergoes chromatin structure changes and confers inducibility on chloramphenicol acetyltransferase gene during activation of $\mathrm{T}$ cells. Mol Cell Biol. 1986;6(9):3042-3049.

20. Zhao K, et al. Rapid and phosphoinositol-dependent binding of the SWI/SNF-like BAF complex to chromatin after $\mathrm{T}$ lymphocyte receptor signaling. Cell. 1998;95(5):625-636.

21. Crabtree GR. Contingent genetic regulatory events in T lymphocyte activation. Science. 1989;243(4889):355-361.

22. Zhang J, et al. The genomic landscape of mantle cell lymphoma is related to the epigenetically determined chromatin state of normal B cells. Blood. 2014;123(19):2988-2996.

23. Yu B, et al. Epigenetic landscapes reveal transcription factors that regulate CD8. Nat Immunol. 2017;18(5):573-582.

24. Crompton JG, et al. Lineage relationship of $\mathrm{CD} 8(+) \mathrm{T}$ cell subsets is revealed by progressive changes in the epigenetic landscape. Cell Mol Immunol. 2016;13(4):502-513.

25. Araki Y, Fann M, Wersto R, Weng NP. Histone acetylation facilitates rapid and robust memory CD8 T cell response through differential expression of effector molecules (eomesodermin and its targets: perforin and granzyme B). J Immunol. 2008;180(12):8102-8108.

26. Russ BE, et al. Distinct epigenetic signatures delineate transcriptional programs during virus-specific $\mathrm{CD} 8(+) \mathrm{T}$ cell differentiation. Immunity. 2014;41(5):853-865.

27. Barski A, et al. Rapid recall ability of memory $\mathrm{T}$ cells is encoded in their epigenome. Sci Rep. 2017;7:39785.

28. Araki Y, et al. Genome-wide analysis of histone methylation reveals chromatin state-based regulation of gene transcription and function of memory CD8 ${ }^{+} \mathrm{T}$ cells. Immunity. 2009;30(6):912-925.

29. Kieffer-Kwon KR, et al. Myc regulates chromatin decompaction and nuclear architecture during $B$ cell activation. Mol Cell. 2017;67(4):566-578.e10.
30. Agarwal S, Rao A. Modulation of chromatin structure regulates cytokine gene expression during $\mathrm{T}$ cell differentiation. Immunity. 1998;9(6):765-775

31. Takemoto N, Koyano-Nakagawa N, Yokota T, Arai N, Miyatake S, Arai K. Th2-specific DNase I-hypersensitive sites in the murine IL-13 and IL-4 intergenic region. Int Immunol. 1998;10(12):1981-1985.

32. Eivazova ER, Aune TM. Dynamic alterations in the conformation of the Ifng gene region during T helper cell differentiation. Proc Natl Acad Sci US A. 2004;101(1):251-256.

33. Placek K, et al. Integration of distinct intracellular signaling pathways at distal regulatory elements directs T-bet expression in human $\mathrm{CD} 4^{+} \mathrm{T}$ cells. JImmunol. 2009;183(12):7743-7751.

34. Bevington SL, et al. Inducible chromatin priming is associated with the establishment of immunological memory in T cells. EMBO J. 2016;35(5):515-535.

35. Scott-Browne JP, et al. Dynamic changes in chromatin accessibility occur in CD8. Immunity. 2016;45(6):1327-1340.

36. Alasoo K, et al. Shared genetic effects on chromatin and gene expression indicate a role for enhancer priming in immune response. $\mathrm{Nat}$ Genet. 2018;50(3):424-431.

37. Samstein RM, et al. Foxp3 exploits a pre-existent enhancer landscape for regulatory $\mathrm{T}$ cell lineage specification. Cell. 2012;151(1):153-166.

38. Foster SL, Hargreaves DC, Medzhitov R. Gene-specific control of inflammation by TLR-induced chromatin modifications. Nature. 2007;447(7147):972-978.

39. Ostuni $R$, et al. Latent enhancers activated by stimulation in differentiated cells. Cell. 2013;152(1-2):157-171.

40. Kaikkonen MU, et al. Remodeling of the enhancer landscape during macrophage activation is coupled to enhancer transcription. Mol Cell. 2013;51(3):310-325.

41. Saeed S, et al. Epigenetic programming of monocyte-to-macrophage differentiation and trained innate immunity. Science. 2014;345(6204):1251086

42. Gosselin D, et al. Environment drives selection and function of enhancers controlling tissue-specific macrophage identities. Cell. 2014;159(6):1327-1340.

43. Dekker J, Misteli T. Long-range chromatin interactions. Cold Spring Harb Perspect Biol. 2015;7(10):a019356.

44. Hewitt SL, Chaumeil J, Skok JA. Chromosome dynamics and the regulation of $\mathrm{V}(\mathrm{D}) \mathrm{J}$ recombination. Immunol Rev. 2010;237(1):43-54.

45. Lee GR, Spilianakis CG, Flavell RA. Hypersensitive site 7 of the TH2 locus control region is essential for expressing TH2 cytokine genes and for long-range intrachromosomal interactions. Nat Immunol. 2005;6(1):42-48.

46. Spilianakis CG, Flavell RA. Long-range intrachromosomal interactions in the Thelper type 2 cytokine locus. Nat Immunol. 2004;5(10):1017-1027.

47. Tsytsykova AV, Rajsbaum R, Falvo JV, Ligeiro F, Neely SR, Goldfeld AE. Activation-dependent intrachromosomal interactions formed by the TNF gene promoter and two distal enhancers. Proc Natl Acad Sci U S A. 2007;104(43):16850-16855.
48. Park JH, Choi Y, Song MJ, Park K, Lee JJ, Kim HP. Dynamic long-range chromatin interaction controls expression of IL-21 in CD $4^{+} \mathrm{T}$ cells. JImmunol. 2016;196(10):4378-4389.

49. Sharaf N, Nicklin MJ, di Giovine FS. Long-range DNA interactions at the IL-1/IL-36/IL-37 gene cluster (2q13) are induced by activation of monocytes. Cytokine. 2014;68(1):16-22.

50. Zhao W, et al. NF-kB- and AP-1-mediated DNA looping regulates osteopontin transcription in endotoxin-stimulated murine macrophages. JImmunol. 2011;186(5):3173-3179.

51. Martin P, et al. Capture Hi-C reveals novel candidate genes and complex long-range interactions with related autoimmune risk loci. Nat Commun 2015;6:10069.

52. Kieffer-Kwon KR, et al. Interactome maps of mouse gene regulatory domains reveal basic principles of transcriptional regulation. Cell. 2013;155(7):1507-1520.

53. Javierre BM, et al. Lineage-specific genome architecture links enhancers and non-coding disease variants to target gene promoters. Cell. 2016;167(5):1369-1384.e19.

54. Phanstiel DH, et al. Static and dynamic DNA loops form AP-1-bound activation hubs during macrophage development. Mol Cell. 2017;67(6):1037-1048.e6.

55. Bunting KL, et al. Multi-tiered reorganization of the genome during B cell affinity maturation anchored by a germinal center-specific locus control region. Immunity. 2016;45(3):497-512.

56. Hu G, et al. Transformation of accessible chromatin and 3D nucleome underlies lineage commitment of early T cells. Immunity. 2018;48(2):227-242.e8.

57. Mumbach MR, et al. Enhancer connectome in primary human cells identifies target genes of disease-associated DNA elements. Nat Genet. 2017;49(11):1602-1612.

58. Lieberman-Aiden E, et al. Comprehensive mapping of long-range interactions reveals folding principles of the human genome. Science. 2009;326(5950):289-293.

59. Davies JO, et al. Multiplexed analysis of chromosome conformation at vastly improved sensitivity. Nat Methods. 2016;13(1):74-80.

60. Fullwood MJ, et al. An oestrogen-receptor-alphabound human chromatin interactome. Nature. 2009;462(7269):58-64.

61. Mumbach MR, et al. HiChIP: efficient and sensitive analysis of protein-directed genome architecture. Nat Methods. 2016;13(11):919-922.

62. Lai B, et al. Trac-looping measures genome structure and chromatin accessibility. Nat Methods. 2018;15(9):741-747.

63. Vermeulen M. Making the most of methylation. Elife. 2013;2:e1387.

64. Yin Y, et al. Impact of cytosine methylation on DNA binding specificities of human transcription factors. Science. 2017;356(6337):eaaj2239.

65. Schübeler D. Function and information content of DNA methylation. Nature. 2015;517(7534):321-326.

66. Hammoud SS, Low DH, Yi C, Carrell DT, Guccione E, Cairns BR. Chromatin and transcription transitions of mammalian adult germline stem cells and spermatogenesis. Cell Stem Cell. 2014;15(2):239-253. 
67. Seisenberger S, et al. The dynamics of genome-wide DNA methylation reprogramming in mouse primordial germ cells. Mol Cell. 2012;48(6):849-862.

68. Lister R, et al. Human DNA methylomes at base resolution show widespread epigenomic differences. Nature. 2009;462(7271):315-322.

69. Lister R, et al. Global epigenomic reconfiguration during mammalian brain development. Science. 2013;341(6146):1237905.

70. Schultz MD, et al. Human body epigenome maps reveal noncanonical DNA methylation variation. Nature. 2015;523(7559):212-216.

71. Schuyler RP, et al. Distinct trends of DNA methylation patterning in the innate and adaptive immune systems. Cell Rep. 2016;17(8):2101-2111.

72. Tahiliani M, et al. Conversion of 5-methylcytosine to 5-hydroxymethylcytosine in mammalian DNA by MLL partner TET1. Science. 2009;324(5929):930-935.

73. Ito $\mathrm{S}$, et al. Tet proteins can convert 5-methylcytosine to 5-formylcytosine and 5-carboxylcytosine. Science. 2011;333(6047):1300-1303.

74. He YF, et al. Tet-mediated formation of 5-carboxylcytosine and its excision by TDG in mammalian DNA. Science. 2011;333(6047):1303-1307.

75. Luo C, Hajkova P, Ecker JR. Dynamic DNA methylation: in the right place at the right time. Science. 2018;361(6409):1336-1340.

76. Morales-Nebreda L, McLafferty FS, Singer BD. DNA methylation as a transcriptional regulator of the immune system. Transl Res. 2019;204:1-18.

77. Cao Q, et al. Inhibiting DNA Methylation by 5-aza-2'-deoxycytidine ameliorates atherosclerosis through suppressing macrophage inflammation. Endocrinology. 2014;155(12):4925-4938.

78. Wang X, Cao Q, Yu L, Shi H, Xue B, Shi H. Epigenetic regulation of macrophage polarization and inflammation by DNA methylation in obesity. JCI Insight. 2016;1(19):e87748.

79. Yang X, Wang X, Liu D, Yu L, Xue B, Shi H. Epigenetic regulation of macrophage polarization by DNA methyltransferase 3b. Mol Endocrinol. 2014;28(4):565-574.

80. Cull AH, Snetsinger B, Buckstein R, Wells RA, Rauh MJ. Tet2 restrains inflammatory gene expression in macrophages. Exp Hematol. 2017;55:56-70.e13.

81. Neves-Costa A, Moita LF. TET1 is a negative transcriptional regulator of IL-1 $\beta$ in the THP- 1 cell line. Mol Immunol. 2013;54(3-4):264-270.

82. Zhang $\mathrm{Q}$, et al. Tet2 is required to resolve inflammation by recruiting $\mathrm{Hdac} 2$ to specifically repress IL-6. Nature. 2015;525(7569):389-393.

83. Fuster JJ, et al. Clonal hematopoiesis associated with TET2 deficiency accelerates atherosclerosis development in mice. Science. 2017;355(6327):842-847.

84. Durek P, et al. Epigenomic profiling of human $\mathrm{CD} 4^{+} \mathrm{T}$ cells supports a linear differentiation model and highlights molecular regulators of memory development. Immunity. 2016;45(5):1148-1161.

85. Abdelsamed HA, et al. Human memory CD8 $\mathrm{T}$ cell effector potential is epigenetically preserved during in vivo homeostasis. J Exp Med. 2017;214(6):1593-1606.

86. Youngblood B, et al. Effector CD8 T cells dedifferentiate into long-lived memory cells. Nature.
2017;552(7685):404-409.

87. Kulis $\mathrm{M}$, et al. Whole-genome fingerprint of the DNA methylome during human B cell differentiation. Nat Genet. 2015;47(7):746-756.

88. Lai AY, et al. DNA methylation profiling in human $\mathrm{B}$ cells reveals immune regulatory elements and epigenetic plasticity at Alu elements during B-cell activation. Genome Res. 2013;23(12):2030-2041.

89. Chen L, et al. Epigenetic and transcriptional programs lead to default IFN- $\gamma$ production by $\gamma \delta \mathrm{T}$ cells. J Immunol. 2007;178(5):2730-2736.

90. Polansky JK, et al. DNA methylation controls Foxp3 gene expression. Eur J Immunol. 2008;38(6):1654-1663.

91. Morris KV, Mattick JS. The rise of regulatory RNA. Nat Rev Genet. 2014;15(6):423-437.

92. Holoch D, Moazed D. RNA-mediated epigenetic regulation of gene expression. Nat Rev Genet. 2015;16(2):71-84

93. Lee RC, Feinbaum RL, Ambros V. The C. elegans heterochronic gene lin-4 encodes small RNAs with antisense complementarity to lin-14. Cell. 1993;75(5):843-854

94. Fire A, Xu S, Montgomery MK, Kostas SA, Driver SE, Mello CC. Potent and specific genetic interference by double-stranded RNA in Caenorhabditis elegans. Nature. 1998;391(6669):806-811.

95. Reinhart BJ, et al. The 21-nucleotide let-7 RNA regulates developmental timing in Caenorhabditis elegans. Nature. 2000;403(6772):901-906

96. Morris KV, Chan SW, Jacobsen SE, Looney DJ. Small interfering RNA-induced transcriptional gene silencing in human cells. Science. 2004;305(5688):1289-1292.

97. Zhao J, Sun BK, Erwin JA, Song JJ, Lee JT. Polycomb proteins targeted by a short repeat RNA to the mouse X chromosome. Science. 2008;322(5902):750-756

98. Lai F, et al. Activating RNAs associate with Mediator to enhance chromatin architecture and transcription. Nature. 2013;494(7438):497-501.

99. Pang KC, et al. Genome-wide identification of long noncoding RNAs in CD8 ${ }^{+} \mathrm{T}$ cells. J Immunol. 2009;182(12):7738-7748.

100. Hu G, et al. Expression and regulation of intergenic long noncoding RNAs during $\mathrm{T}$ cell development and differentiation. Nat Immunol. 2013;14(11):1190-1198.

101.IIott NE, et al. Long non-coding RNAs and enhancer RNAs regulate the lipopolysaccharide-induced inflammatory response in human monocytes. Nat Commun. 2014;5:3979.

102. Carpenter S, et al. A long noncoding RNA mediates both activation and repression of immune response genes. Science. 2013;341(6147):789-792.

103. Li Z, et al. The long noncoding RNA THRIL regulates TNF $\alpha$ expression through its interaction with hnRNPL. Proc Natl Acad Sci U S A. 2014;111(3):1002-1007.

104.Cui $\mathrm{H}$, et al. The human long noncoding RNA lnc-IL7R regulates the inflammatory response. Eur J Immunol. 2014;44(7):2085-2095.

105. Gomez JA, et al. The NeST long ncRNA controls microbial susceptibility and epigenetic activation of the interferon- $\gamma$ locus. Cell. 2013;152(4):743-754.

106.Almouzni G, Cedar H. Maintenance of epigenetic information. Cold Spring Harb Perspect Biol. 2016;8(5):a019372.
107. Johnson JL, et al. Lineage-determining transcription factor TCF- 1 initiates the epigenetic identity of T cells. Immunity. 2018;48(2):243-257.e10.

108. Mandal M, et al. BRWD1 orchestrates epigenetic landscape of late B lymphopoiesis. Nat Commun. 2018;9(1):3888.

109. Serhan CN, Levy BD. Resolvins in inflammation: emergence of the pro-resolving superfamily of mediators. JClin Invest. 2018;128(7):2657-2669.

110.Levy BD, Serhan CN. Resolution of acute inflammation in the lung. Annu Rev Physiol. 2014;76:467-492.

111. Oishi Y, et al. SREBP1 contributes to resolution of pro-inflammatory TLR4 signaling by reprogramming fatty acid metabolism. Cell Metab. 2017;25(2):412-427.

112. Lavin Y, Mortha A, Rahman A, Merad M. Regulation of macrophage development and function in peripheral tissues. Nat Rev Immunol. 2015;15(12):731-744.

113. Amit I, Winter DR, Jung S. The role of the local environment and epigenetics in shaping macrophage identity and their effect on tissue homeostasis. Nat Immunol. 2016;17(1):18-25.

114. Glass CK, Natoli G. Molecular control of activation and priming in macrophages. Nat Immunol. 2016;17(1):26-33.

115. Lavin Y, et al. Tissue-resident macrophage enhancer landscapes are shaped by the local microenvironment. Cell. 2014;159(6):1312-1326.

116. Mass E, et al. Specification of tissue-resident macrophages during organogenesis. Science. 2016;353(6304):aaf4238.

117. Jantsch J, et al. Cutaneous $\mathrm{Na}^{+}$storage strengthens the antimicrobial barrier function of the skin and boosts macrophage-driven host defense. Cell Metab. 2015;21(3):493-501.

118. Binger KJ, et al. High salt reduces the activation of IL-4- and IL-13-stimulated macrophages. JClin Invest. 2015;125(11):4223-4238.

119. Ng GY, Lim YA, Sobey CG, Dheen T, Fann DY, Arumugam TV. Epigenetic regulation of inflammation in stroke. Ther Adv Neurol Disord. 2018;11:1756286418771815.

120. Valencia-Morales Mdel P, et al. The DNA methylation drift of the atherosclerotic aorta increases with lesion progression. BMC Med Genomics. 2015;8:7.

121. Endres $\mathrm{M}$, et al. DNA methyltransferase contributes to delayed ischemic brain injury. JNeurosci. 2000;20(9):3175-3181.

122. Gallego-Fabrega $\mathrm{C}$, et al. TRAF3 epigenetic regulation is associated with vascular recurrence in patients with ischemic stroke. Stroke. 2016;47(5):1180-1186.

123. Gallego-Fabrega C, et al. PPM1A methylation is associated with vascular recurrence in aspirin-treated patients. Stroke. 2016;47(7):1926-1929.

124. Baccarelli A, et al. Repetitive element DNA methylation and circulating endothelial and inflammation markers in the VA normative aging study. Epigenetics. 2010;5(3):222-228.

125. Udali S, Guarini P, Moruzzi S, Choi SW, Friso S. Cardiovascular epigenetics: from DNA methylation to microRNAs. Mol Aspects Med. 2013;34(4):883-901.

126. Lawler J. Thrombospondin-1 as an endogenous inhibitor of angiogenesis and tumor growth. 
JCell Mol Med. 2002;6(1):1-12.

127. Lawler PR, Lawler J. Molecular basis for the regulation of angiogenesis by thrombospondin-1 and -2. Cold Spring Harb Perspect Med. 2012;2(5):a006627.

128. Lopez-Dee Z, Pidcock K, Gutierrez LS. Thrombospondin-1: multiple paths to inflammation. Mediators Inflamm. 2011;2011:296069.

129. Cardoso AL, Guedes JR, Pereira de Almeida L, Pedroso de Lima MC. miR-155 modulates microglia-mediated immune response by down-regulating SOCS-1 and promoting cytokine and nitric oxide production. Immunology. 2012;135(1):73-88.

130. Guedes J, Cardoso AL, Pedroso de Lima MC. Involvement of microRNA in microgliamediated immune response. Clin Dev Immunol. 2013;2013:186872.

131. Cho KJ, Song J, Oh Y, Lee JE. MicroRNA-Let-7a regulates the function of microglia in inflammation. Mol Cell Neurosci. 2015;68:167-176.

132. Khoshnam SE, Winlow W, Farbood Y, Moghaddam HF, Farzaneh M. Emerging roles of microRNAs in ischemic stroke: as possible therapeutic agents. J Stroke. 2017;19(2):166-187.

133. Di Francesco A, et al. Global changes in DNA methylation in Alzheimer's disease peripheral blood mononuclear cells. Brain Behav Immun. 2015;45:139-144.

134. Chakraborty K, et al. The mito-DAMP cardiolipin blocks IL-10 production causing persistent inflammation during bacterial pneumonia. Nat Commun. 2017;8:13944.

135. Hoeksema MA, et al. Targeting macrophage histone deacetylase 3 stabilizes atherosclerotic lesions. EMBO Mol Med. 2014;6(9):1124-1132.

136. Kuboyama T, et al. HDAC3 inhibition ameliorates spinal cord injury by immunomodulation. Sci Rep. 2017;7(1):8641.

137. Deyhle MR, Hyldahl RD. The role of T lymphocytes in skeletal muscle repair from traumatic and contraction-induced injury. Front Physiol. 2018;9:768.

138.Zhang C, Li L, Feng K, Fan D, Xue W, Lu J. 'Repair' Treg cells in tissue injury. Cell Physiol Biochem. 2017;43(6):2155-2169.

139. Toben D, et al. Fracture healing is accelerated in the absence of the adaptive immune system. J Bone Miner Res. 2011;26(1):113-124.

140. Nam D, et al. T-lymphocytes enable osteoblast maturation via IL-17F during the early phase of fracture repair. PLoS One. 2012;7(6):e40044.

141. Burzyn D, et al. A special population of regulatory $\mathrm{T}$ cells potentiates muscle repair. Cell. 2013;155(6):1282-1295.

142. Liu Y, et al. Mesenchymal stem cell-based tissue regeneration is governed by recipient $\mathrm{T}$ lymphocytes via IFN- $\gamma$ and TNF- $\alpha$. Nat Med. 2011;17(12):1594-1601.

143. Reinke S, et al. Terminally differentiated $\mathrm{CD} 8^{+}$ $\mathrm{T}$ cells negatively affect bone regeneration in humans. Sci Transl Med. 2013;5(177):177ra36.

144.Walsh JT, et al. MHCII-independent $\mathrm{CD} 4^{+} \mathrm{T}$ cells protect injured CNS neurons via IL-4. J Clin Invest. 2015;125(2):699-714.

145. Baudoux T, et al. $\mathrm{CD} 4^{+}$and $\mathrm{CD} 8^{+} \mathrm{T}$ cells exert regulatory properties during experimental acute aristolochic acid nephropathy. Sci Rep.
2018;8(1):5334.

146. Hofmann $\mathrm{U}$, et al. Activation of $\mathrm{CD} 4^{+} \mathrm{T}$ lymphocytes improves wound healing and survival after experimental myocardial infarction in mice. Circulation. 2012;125(13):1652-1663.

147. Yang XP, et al. EZH2 is crucial for both differentiation of regulatory $\mathrm{T}$ cells and $\mathrm{T}$ effector cell expansion. Sci Rep. 2015;5:10643.

148.Li L, Zhang Y, Xu M, Rong R, Wang J, Zhu T. Inhibition of histone methyltransferase EZH2 ameliorates early acute renal allograft rejection in rats. BMC Immunol. 2016;17(1):41.

149. He S, et al. Inhibition of histone methylation arrests ongoing graft-versus-host disease in mice by selectively inducing apoptosis of alloreactive effector T cells. Blood. 2012;119(5):1274-1282.

150. Harrison OJ, et al. Commensal-specific T cell plasticity promotes rapid tissue adaptation to injury. Science. 2019;363(6422):eaat6280.

151. Sharp LL, Jameson JM, Cauvi G, Havran WL. Dendritic epidermal $\mathrm{T}$ cells regulate skin homeostasis through local production of insulin-like growth factor 1. Nat Immunol. 2005;6(1):73-79.

152. Boismenu R, Feng L, Xia YY, Chang JC, Havran WL. Chemokine expression by intraepithelial $\gamma \delta \mathrm{T}$ cells. Implications for the recruitment of inflammatory cells to damaged epithelia. JImmunol. 1996;157(3):985-992.

153. Jameson J, et al. A role for skin $\gamma \delta \mathrm{T}$ cells in wound repair. Science. 2002;296(5568):747-749.

154.Simonian PL, Wehrmann F, Roark CL, Born WK, O'Brien RL, Fontenot AP. $\gamma \delta$ T cells protect against lung fibrosis via IL-22. J Exp Med. 2010;207(10):2239-2253.

155. Ono T, et al. IL-17-producing $\gamma \delta \mathrm{T}$ cells enhance bone regeneration. Nat Commun. 2016;7:10928.

156.Schmolka N, Wencker M, Hayday AC, Silva-Santos B. Epigenetic and transcriptional regulation of $\gamma \delta$ T cell differentiation: Programming cells for responses in time and space. Semin Immunol. 2015;27(1):19-25.

157. Schmolka N, et al. Epigenetic and transcriptional signatures of stable versus plastic differentiation of proinflammatory $\gamma \delta \mathrm{T}$ cell subsets. Nat Immunol. 2013;14(10):1093-1100.

158. Ismahil MA, Hamid T, Bansal SS, Patel B, Kingery JR, Prabhu SD. Remodeling of the mononuclear phagocyte network underlies chronic inflammation and disease progression in heart failure: critical importance of the cardiosplenic axis. Circ Res. 2014;114(2):266-282.

159. Bansal SS, et al. Activated T lymphocytes are essential drivers of pathological remodeling in ischemic heart failure. Circ Heart Fail. 2017;10(3):e003688.

160. Kleijwegt FS, et al. Transfer of regulatory properties from tolerogenic to proinflammatory dendritic cells via induced autoreactive regulatory $\mathrm{T}$ cells. JImmunol. 2011;187(12):6357-6364.

161. D'Alessio FR, et al. CD $4^{+} \mathrm{CD} 25^{+}{ }^{+} \mathrm{Foxp}^{+}{ }^{+}$Tregs resolve experimental lung injury in mice and are present in humans with acute lung injury. J Clin Invest. 2009;119(10):2898-2913.

162.Aggarwal NR, et al. Regulatory $\mathrm{T}$ cell-mediated resolution of lung injury: identification of potential target genes via expression profiling. Physiol Genomics. 2010;41(2):109-119.

163. Kinsey GR, et al. Regulatory $\mathrm{T}$ cells suppress innate immunity in kidney ischemia-reperfusion injury. J Am Soc Nephrol. 2009;20(8):1744-1753.

164. Lai LW, Yong KC, Lien YH. Pharmacologic recruitment of regulatory $\mathrm{T}$ cells as a therapy for ischemic acute kidney injury. Kidney Int . 2012;81(10):983-992.

165. Dombrowski Y, et al. Regulatory T cells promote myelin regeneration in the central nervous system. Nat Neurosci. 2017;20(5):674-680.

166. Meng $X$, et al. Regulatory $T$ cells in cardiovascular diseases. Nat Rev Cardiol. 2016;13(3):167-179.

167. Weirather J, et al. Foxp $3^{+} \mathrm{CD} 4^{+} \mathrm{T}$ cells improve healing after myocardial infarction by modulating monocyte/macrophage differentiation. Circ Res. 2014;115(1):55-67.

168. Singer BD, et al. Regulatory T cell DNA methyltransferase inhibition accelerates resolution of lung inflammation. Am J Respir Cell Mol Biol. 2015;52(5):641-652.

169.Artis D, Spits H. The biology of innate lymphoid cells. Nature. 2015;517(7534):293-301.

170. Monticelli LA, et al. Innate lymphoid cells promote lung-tissue homeostasis after infection with influenza virus. Nat Immunol. 2011;12(11):1045-1054.

171. Liu J, et al. Local group 2 innate lymphoid cells promote corneal regeneration after epithelial abrasion. Am J Pathol. 2017;187(6):1313-1326.

172. Shih HY, et al. Developmental acquisition of regulomes underlies innate lymphoid cell functionality. Cell. 2016;165(5):1120-1133.

173. Gury-BenAri M, et al. The spectrum and regulatory landscape of intestinal innate lymphoid cells are shaped by the microbiome. Cell. 2016;166(5):1231-1246.e13

174. Engelhardt JF. Stem cell niches in the mouse airway. Am JRespir Cell Mol Biol. 2001;24(6):649-652.

175. Epelman S, Liu PP, Mann DL. Role of innate and adaptive immune mechanisms in cardiac injury and repair. Nat Rev Immunol. 2015;15(2):117-129.

176. Pellicoro A, Ramachandran P, Iredale JP, Fallowfield JA. Liver fibrosis and repair: immune regulation of wound healing in a solid organ. Nat Rev Immunol. 2014;14(3):181-194.

177. Chen L, et al. Genetic drivers of epigenetic and transcriptional variation in human immune cells. Cell. 2016;167(5):1398-1414.e24.

178. Bajpai G, et al. Tissue resident CCR2 and CCR $2^{+}$cardiac macrophages differentially orchestrate monocyte recruitment and fate specification following myocardial injury. Circ Res. 2019;124(2):263-278.

179. Schultze JL. Myocardial infarction cell by cell. Nat Immunol. 2019;20(1):7-9.

180. Bassler K, Schulte-Schrepping J, Warnat-Herresthal S, Aschenbrenner AC, Schultze JL. The myeloid cell compartment-cell by cell. Annu Rev Immunol. 2019;37:269-293.

181. Hasin Y, Seldin M, Lusis A. Multi-omics approaches to disease. Genome Biol.2017;18(1):83.

182. Kelsey G, Stegle O, Reik W. Single-cell epigenomics: recording the past and predicting the future. Science. 2017;358(6359):69-75.

183. Buenrostro JD, et al. Single-cell chromatin accessibility reveals principles of regulatory variation. Nature. 2015;523(7561):486-490.

184.Jin W, et al. Genome-wide detection of DNase I hypersensitive sites in single cells and FFPE tis- 
sue samples. Nature. 2015;528(7580):142-146. 185. Lai B, et al. Principles of nucleosome organization revealed by single-cell micrococcal nuclease sequencing. Nature. 2018;562(7726):281-285.

186. WHO. Global Health Estimates 2016: Deaths by Cause, Age, Sex, by Country by Region, 20002016. Geneva, Switzerland: WHO; 2018.

187. Kessler T, Vilne B, Schunkert H. The impact of genome-wide association studies on the pathophysiology and therapy of cardiovascular disease. EMBO Mol Med. 2016;8(7):688-701.

188. Helgadottir A, et al. A common variant on chromosome 9p21 affects the risk of myocardial infarction. Science. 2007;316(5830):1491-1493.

189. Perdigoto C. Genetic variation: putting causal variants on the map. Nat Rev Genet. 2018;19(4):188-189.

190.She R, Jarosz DF. Mapping causal variants with single-nucleotide resolution reveals biochemical drivers of phenotypic change. Cell. 2018;172(3):478-490.e15.

191. Marian AJ. Causality in genetics: the gradient of genetic effects and back to Koch's postulates of causality. Circ Res. 2014;114(2):e18-e21.

192. Holdt LM, et al. Alu elements in ANRIL non-coding RNA at chromosome 9p21 modulate atherogenic cell functions through trans-regulation of gene networks. PLoS Genet. 2013;9(7):e1003588.

193. Russell-Hallinan A, Watson CJ, Baugh JA. Epigenetics of aberrant cardiac wound healing. Compr Physiol. 2018;8(2):451-491.

194.Greco CM, Condorelli G. Epigenetic modifications and noncoding RNAs in cardiac hypertrophy and failure. Nat Rev Cardiol. 2015;12(8):488-497.

195. Movassagh M, et al. Distinct epigenomic features in end-stage failing human hearts. Circulation. 2011;124(22):2411-2422.

196. Kaneda R, et al. Genome-wide histone methylation profile for heart failure. Genes Cells. 2009;14(1):69-77.

197. Kim YS, et al. Protective role of 5-azacytidine on myocardial infarction is associated with modulation of macrophage phenotype and inhibition of fibrosis. J Cell Mol Med. 2014;18(6):1018-1027.

198. Lawrence T, Natoli G. Transcriptional regulation of macrophage polarization: enabling diversity with identity. Nat Rev Immunol. 2011;11(11):750-761.

199. Quaife-Ryan GA, et al. Multicellular transcriptional analysis of mammalian heart regeneration. Circulation. 2017;136(12):1123-1139.

200.Dick SA, et al. Self-renewing resident cardiac macrophages limit adverse remodeling following myocardial infarction. Nat Immunol. 2019;20(1):29-39. 